\title{
OBSESSION SUBTYPES: RELATIONSHIPS WITH OBSESSIVE-COMPULSIVE SYMPTOMS, DYSFUNCTIONAL BELIEFS AND THOUGHT CONTROL STRATEGIES
}

\author{
Amparo Belloch ${ }^{1}$, Carmen Morillo ${ }^{2}$, and Gemma Garcia-Soriano ${ }^{1}$ \\ ${ }^{1}$ Universidad de Valencia \\ ¿ Universidad Jaime I, de Castellón
}

\begin{abstract}
Obsessive themes can be classified into two main categories: autogenous obsessions and reactive obsessions. The first comprise highly unacceptable and unrealistic thoughts, including aggressive, sexual and repulsive concerns, that can be conceptualised as «pure obsessions» (PO). whereas the second relate to relatively realistic doubts or thoughts with common themes dealing with contamination, mistakes or accidents, associated with overt actions taken to prevent the occurrence of negative outcomes, that can be conceptualised as obsessions plus compulsions $(\mathrm{O}-\mathrm{C})$. In this study, the differences between PO and $\mathrm{O}-\mathrm{C}$ in 39 Obsessive-Compulsive Disordered (OCD) outpatients are examined. Results: the O-C subtype associated with higher OCD severity and obsessive-compulsive symptom measures, whereas the $\mathrm{PO}$ subtype related to harming impulses only. $\mathrm{PO}$ also showed a significant relationship with dysfunctional beliefs as to responsibility, overestimation of threat and meta-cognitive beliefs (thought-action fusion. importance of thoughts and the control over them ), as well as with a tendency to the concealment of obsessions. O-C only related to worry as a thought control strategy.
\end{abstract}

Keywords: Pure obsessions, Autogenous obsessions, Reactive obsessions, Obsessive-Compulsive Disorder, OCD subtypes, Obsessive dysfunctional beliefs, Thought control strategies.

\section{Subtipos de obsesiones y su relación con sintomas obsesivo-compulsivos, creencias disfuncionales y estrategias de control}

Resumen: Los temas obsesivos pueden clasificarse en dos grandes categorías: «Autógenos» (OA) $y$ «Reactivos» (OR). Los primeros refieren a contenidos sexuales, agresivos, o religiosos, y los reactivos incluyen contenidos de contaminación, errores, accidentes, o desorden, y se acompañan de acciones compulsivas manifiestas dirigidas a la prevención de sucesos negativos. Este trabajo estudia la diferenciación entre OA y OR en 39 pacientes con Trastorno Obsesivo-Compulsivo (TOC). Resultados: las OR se asocian a una mayor gravedad del TOC y a medidas globales de síntomas obsesivo-compulsivos, mientras que las $\mathrm{OA}$ se asociaron solamente con impulsos obsesivos. A su vez, estas mostraron relaciones significativas con creencias disfuncionales de responsabilidad, sobreestimación del peligro, y con creencias meta-cognitivas (fusión pensamiento-acción, importancia de los pensamientos y de su control), así como con una tendencia a ocultar los pensamientos. Las obsesiones reactivas únicamente se relacionaron con la preocupación como estrategia de control de los pensamientos.

Palabras clave: Obsesiones puras, obsesiones autógenas, obsesiones reactivas, trastorno obsesivo-compulsivo (TOC), subtipos de obsesiones, creencias obsesivas disfuncionales, estrategias de control.

\section{INTRODUCTION}

Although obsessive-compulsive disorder (OCD) is conceived as a unitary nosological entity in the

Received 11 November 2005; accepted 14 March 2006.

Correspondence: Amparo Belloch, Departamento de Personalidad, Evaluación y Tratamientos Psicológicos. Facultad de Psicología, Avda. Blasco Ibáñez 21, 46010 Valencia (Spain) E-mail amparo.belloch $(a)$ uv.es current standard nomenclatures (DSM-IV and ICD$10)$, there is considerable clinical consensus about its heterogeneity as manifested by symptom subgroups, subtypes of obsessions and clusters of $O C D$

\footnotetext{
Acknowledgements: This study was supported by the Spanish Ministerio de Ciencia y Tecnología and EC Feder founds (Grant no. BSO2002-02330). The authors wish to thank Dr. David A. Clark and Dr. Christine Purdon for their kind permission to translate the Ohsessional Intrusions Inventon-Revised (ROII) into Spanish.
} 
patients. This consensus can be verified in the theoretical formulations about the aetiology and/or maintenance of OCD manifestations, as well as in the various cognitive approaches that focus on the specific presentations of OCD symptoms. From this perspective, Rachman $(1997,1998,2002)$ has postulated different cognitive formulations for «pure obsessions» and «checkers» OCD-patients. This author has suggested that catastrophic misinterpretations of thoughts are highly relevant in explaining «pure obsessions», whereas compulsive checking behaviours are related to excessive responsibility and to the over-estimation of the probability and seriousness of harm, and the dysfunctional cognitions associated with fear of contamination are a key factor in contamination/washing. Other authors have postulated specific cognitive formulations for hoarding symptoms (Frost \& Steketee, 2000; Kyrios, Steketee, Frost, \& Oh, 2002). However, empirical research about the above-mentioned hypotheses is still scarce. The findings from some correlational studies suggest that different presentations of obsessive-compulsive symptoms may be especially associated with different OCD-related beliefs (Emmelkamp, \& Aardema, 1999; Faull, Joseph, Meaden, \& Lawrence, 2004; Taylor et al., 2006; Tolin, Woods, \& Abramowitz, 2003), using data obtained from non-clinical participants.

An additional difficulty in the research about the OCD subtypes is the absence of an adequate consensus on the classification or taxonomy of OCDpatients and OCD symptoms. From this point of view, at least three different questions must be answered: how many distinct $O C D$ subtypes should be reasonably postulated?; Are there different cognitive and meta-cognitive factors underlying these subtypes?; and, How are the subtypes best considered, from a categorical or from a dimensional point of view?

Several approaches for subtyping OCD have been proposed. On the one hand, there are rationally-based taxonomies (Kozak, Foa, \& McCarthy, 1988; Marks, 1987).These are symptom-based classifications that emphasize a single dominant compulsion (e.g. washing, checking, etc.) or the absence of compulsive behaviours (e.g. "obsessives", or "obsessionals"). On the other hand, there are empirically-derived classifications using exploratory and confirmatory factor analysis (Denys, de Geus, van Megen, \& Westnberg, 2004; Mataix, Rauch, Manzo, Jenije, \& Baer, 1999; Summerfeldt, Richter, Antony, \& Swinson, 1999), or cluster analysis
(Abramowitz, Franklin, Schwartz, \& Furr, 2003; Calamari, Wiegartz, \& Janeck, 1999; Calamari et al., 2004) to identify OCD subtypes. These formulations have been derived from studies with normal participants, as well as clinical OCD subjects, as target samples. Some subgroups or subtypes have been consistently identified across these studies, including not only obsessive themes but associated behaviours as well (Abramowitz, Whiteside, Lynam, \& Kalsy, 2003; Leckman et al., 1997; Summerfeldt et al., 1999): obsessions with aggressive, sexual, religious and somatic themes, with checking behaviours; symmetry obsessions with ordering/ arranging, counting and repeating rituals; contamination obsessions and cleaning rituals; and hoarding obsessions with hoarding and collecting behaviours. However, substantial inconsistencies have been also observed among these studies.

A somewhat different approach to the heterogeneity of the OCD has recently been suggested by Lee \& Kwon (2003). These authors have proposed an obsession model that classifies obsessions into two subtypes, namely «autogenous " or «reactive», on the basis of their contents, which elicit different emotional reactions, evaluative appraisals and control strategies (Lee \& Telch, 2005). The main source of differences between the two modalities refers above all to the obsessional themes: common themes of autogenous obsessions $(\mathrm{AO})$ would be aggressive, sexual, blasphemous/immoral and aversive images, thoughts or impulses, and they could be the basis for developing a pure obsessive disorder. In contrast, typical reactive obsession (RO) themes would be contamination, mistakes, accidents, asymmetry or disarray, and they could lead to compulsions such as washing, checking, ordering or hoarding. Besides these differences, the authors propose other characteristics, such as the identifiability of the evoking stimuli, the egodystonity caused by the obsessions and/or compulsions, and the perceived rationality of the obsessive thought content. The autogenous themes resemble a cluster of OCD symptoms identified in most of the studies (Mataix, Rosario, \& Leckman, 2005). They are undoubtedly related to the classic concept of «pure obsessions"), characterized as a pure cognitive disorder and as a symptom of OCD (Rachman \& Hodgson, 1980; Rachman \& Shafran, 1998) and the focus of Rachman's cognitive theory about obsessions (Rachman, 1997, 1998, 2003).

To date, the published empirical evidence about the AO/RO model of obsessions has been mainly 
based on normal samples. The general aim of the current study was to test the AO/RO model on a group of OCD patients, taking as a starting point the consideration of $A O$ and $\mathrm{RO}$ from a dimensional approach. From this general aim, our purposes were two-fold. The first was to examine the relationships of $\mathrm{AO}$ and $\mathrm{RO}$ themes with different modalities of obsessive-compulsive symptoms, worrisome thinking and depressive symptoms and cognitions (e.g. negative automatic thoughts). The second was to explore the association of $\mathrm{AO}$ and RO with general cognitive and meta-cognitive variables, that is, OCD-related dysfunctional beliefs and thought control strategies.

\section{METHOD}

\section{Participants}

Thirty-nine subjects ( 14 men and 25 women) with a primary axis I DSM-IV (APA, 2000) diagnosis of OCD were recruited from a consecutive series of patients admitted to the Outpatient mental-health clinic of three general hospitals in Valencia, Spain. Their mean age was 32 years (SD $=9.8$, range from 16 to 69 years), with $60 \%$ of the participants aged between 22 and 35 years. On average, the duration of the OCD was 6.1 years $(\mathrm{SD}=5.8)$. At the time of the study, $91 \%$ of the patients were receiving pharmacological treatment with an SRI ( $86 \%$ of cases) or tricyclic ( $4 \%$ of cases) antidepressant. Taking into account the total score on the Y-BOCS severity scale, $38 \%$ of the patients had a moderate OCD (Y-BOCS scores: $16-23$ ), $38 \%$ of the patients were severe (YBOCS scores: $24-31$ ), and $24 \%$ had a very severe OCD (Y-BOCS scores 32-40).

\section{Measures}

All the subjects were administered an initial standardised interview recording basic demographic data (age, gender, occupation, educational level, socio-economic status) and relevant data from their case histories: years of $O C D$ duration, current pharmacological treatment and psychological and/or pharmacological treatments received in the proceding five years for OCD and/or other mental disorders. Next, the ADIS-IV (Di Nardo, Brown, \& Bar- low, 1994) was used in order to confirm or discard the clinical OCD diagnosis, as well as the content and modality of the most disturbing obsessions, that is, $\mathrm{PO}$ or O-C. Patients were also screened for the presence of additional mood and anxiety symptoms and/or disorders. If co-morbidity was suspected, additional diagnoses were made on the basis of the DSM-IV criteria.

The Yale-Brown Obsessive-Compulsive Severity Scale (Y-BOCS; Goodman, Price, Rasmussen, \& Mazure, 1989a, 1989b) is considered the standard severity measure of $O C D$. It contains 10 items, 5 for obsessions and 5 for compulsions. Each symptom is rated for frequency or duration, interference, distress, resistance and perceived control on a scale from 0 (none) to 4 (extreme). Two subscales are obtained, Obsessions and Compulsions, each ranging from 0 (no symptoms) to 20 (severe). A total score (from 0 to 40 ) is also obtained by adding the 5 obsession items and the 5 compulsion items. Inter-rater reliability for this instrument has been shown to be excellent (Total Y-BOCS score $=.98$, $\mathrm{p}<0.001$; Goodman et al., 1989a).

Maudsley Obsessive Compulsive Inventory (MOCI; Hodgson \& Rachman, 1977; Rachman \& Hodgson, 1980). This is a widely used self-report questionnaire that evaluates obsessive-compulsive symptomatology. It consists of 30 true/false items describing various obsessive-compulsive symptoms, such as Washing, Checking, Repetition and Doubting. The MOCI mainly assesses overt compulsive symptoms.

Padua Inventory-Washington State University Revision (PI-WSUR; Burns, Keortge, Formes, \& Sternberg, 1996). This is a 39-item self-report measure of obsessions and compulsions. Each item is rated on a 5-point scale according to the degree of disturbance caused by the thought or behaviour ( 0 $=$ (not at all» to $4=$ (very much $\rangle)$. The items were distributed into 5 content domains relevant to $O C D$ : Obsessional thoughts about harm to self/others, obsessional impulses to harm self/others, contamination obsessions and washing compulsions, checking compulsions, and dressing/grooming compulsions. The Spanish version of the instrument was applied (Ibañez, Olmedo, Peñate, \& González, 2002).

Revised Obsessional.Intrusions Imventory (ROII; Purdon \& Clark, 1993, 1994). This is a self-report questionnaire designed to assess the frequency of 52 unwanted intrusive thoughts, images and impulses, analogous to clinical obsessions (part 1), as well 
the appraisals and control strategies associated with the most upsetting intrusive thought referred to by the subjects (part 2). Respondents rate each unwanted intrusive thought on a 7-point scale from 0 ( $(1)$ have never had this thought") to 6 ("I have this thought frequently during the day"). A ROII total score (frequency of intrusive thoughts) is derived by adding the scale scores for the 52 items. In the Spanish version of the instrument (Belloch et al., 2004; Morillo et al., 2003) a two-factorial solution was obtained. The first factor included 41 intrusive thoughts on aggression and sexual and socially unacceptable behaviours (items 1 to 21 , and 25 to 44), whereas the second factor contained 11 intrusive thoughts referring to doubts, fears of contamination and checking behaviours (items 22 to 24, and 45 to 52). For data analyses, subscale frequency scores were computed separately for each factor. The first factor is labelled as «pure obsessions» (PO)», and the second factor is called as uobsessions and compulsions》 ( $\mathrm{O}-\mathrm{C})$.

Obsessive Beliefs Imventory (Inventario de Creencias Obsesivas, ICO; Belloch, Cabedo, Morillo, Lucero, \& Carrió, 2003; Cabedo, Belloch, Morillo, Giménez, \& Carrió, 2004; Giménez, Morillo, Belloch, Carrió, \& Cabedo, 2004; Carrió, 2004). This is an 82-item self-report questionnaire designed to evaluate dysfunctional beliefs hypothetically related to the maintenance and/or development of the OCD. It was designed following the preliminary work of the Obsessive Compulsive Cognitions Working Group (OCCWG, 1997, 2001), with some items originally developed to tap the six dimensions proposed by this group, and some items derived from other previously created instruments, such as the Thought-Action Fusion Scale (Shafran, Thordarson, \& Rachman, 1996) and the Responsibility Attitude Scale (Salkovskis et al., 2000). Participants were asked to rate whether they agree or not (7point Likert scales from $0=$ «Absolutely disagree» to $7=$ «Absolutely agree $)$ with different sentences corresponding to general dysfunctional beliefs. The ICO contains eight subscales: 1) Inflated responsibility; 2) Over-importance of thoughts, in restricted sense; 3) Likelihood Thought-action fusion (LTAF); 4) Moral Thought-action fusion (M-TAF); 5) Importance of thought control; 6) Over-estimation of harm or threat; 7) Intolerance of uncertainty; and, 8) Perfectionism. The instrument showed an excellent internal consistency ( \pm range values from 0.75 to 0.89 ; Total score $\pm=0.94$ ) and temporal stability (Intraclass Correlation Coefficient) for the total score $(\mathrm{ICC}=0.80)$, and for the eight subscales (ICC values ranged between 0.70 and 0.93 ). All subscales successfully discriminated between sub-clinical OCD subjects (according to the MOCI score) and normal participants.

White Bear Suppression Inventory (WBSI; Wegner \& Zanakos, 1994). This is a 15-item self-report inventory that measures the chronic tendency to suppress negative and/or unwanted thoughts in general. WBSI items are scored on a 5-point Likert scale from $1=$ «Absolutely disagree» to $5=$ «Absolutely agree». We have used the Spanish version of the WBSI, which showed good psychometric properties (Lucero, 2002; Luciano et al., in press)

Thought Control Questionnaire (TCQ; Wells \& Davies, 1994). This 30-item self-report instrument assesses the frequency of different strategies used to control unpleasant and unwanted thoughts in general. The strategies are grouped into five analytically derived subscales: Distraction, Punishment, Reappraisal, Social control and Worry. Items are scored on a 4-point Likert scale from $1=$ «Neven to $4=$ «Almost always»). We used the validated Spanish version of this questionnaire (Lucero, 2002; Luciano et al., in press).

Beck Depression Inventory (BDI; Beck, Rush, Shaw, \& Emery, 1979). This is a self-report instrument that has been widely used and validated to measure depressive symptoms. Subjects have to rate the severity of 21 depressive symptoms on a 4-point scale ranging from 0 (symptom not present) to 3 (symptom very intense). BDI total scores range between 0 and 63.

Automatic Thoughts Questionnaire (ATT; Hollon \& Kendall, 1980). The ATQ is a 30-item self-report inventory that assesses the frequency of the occurrence of different negative automatic thoughts typically associated with depressive states, using a Likert scale from 1 («Neven)) to 5 («All the time»).

Penn State Worry Questionnaire (PSWQ; Meyer, Miller, Metzger, \& Borkovec, 1990). This is a 16item self-report inventory that assesses excessive and uncontrollable worry. The items focus on the excessiveness, duration and uncontrollability of worry and related distress. Each item is rated on a 5-point scale ( $1=$ «not at all typical of me» to $5=$ "Very typical of me»). The Spanish validated version was applied (Sandin \& Chorot, 1991). 


\section{Procedure}

Participants were eligible to be included in the study if they had not changed their medication regimen during the past 4 weeks, and if they did not suffer from any major mental disorder or substance-abuse-related disorder apart from OCD. Information related to the purpose of the study and a brief description of the assessment process involved was presented before the participants completed the evaluation instruments, in order to obtain their informed consent. All the patients were individually interviewed by a qualified clinical psychologist (A.B. or C.M.), which also decides about the characterization of the patient as pure obsessive (PO) or as obsessive and compulsive $(\mathrm{O}-\mathrm{C})$. Participants received the Y-BOCS as a part of the diagnostic interview. All the patients were evaluated before they participated in a cognitive-behavioural treatment program.

\section{RESULTS}

Table 1 shows the descriptive statistics of the OCD subjects on the study measures, taking into account the gender of the subjects. Independent sample $t$-tests indicated that men obtained higher scores than women on only two measures: the total score on the ROII $(t=2.46 ; p=0.02)$, and the PO subscale $(t=2.27 ; p=0.02)$.

As a whole, the OCD severity of patients could be classified as severe on the basis of the OCD measures (Y-BOCS, MOCI and Padua Inventory). As for the depression measure (BDI), the mean score obtained indicated that the patients did not have clinically significant depressive symptoms.

Associations among $P O$ and $O-C$ obsessions and measures of $O C D$ symptoms, depression and worry

To test the associations of $\mathrm{PO}$ and $\mathrm{O}-\mathrm{C}$ obsessions with measures of obsessive-compulsive symptoms, zero-order correlations among the $\mathrm{PO}$ and $\mathrm{O}$ $\mathrm{C}$ scores on the ROII and the Y-BOCS, MOCI and PI-WSUR scales were computed. Correlation coefficients were also calculated for the measures of depressive symptoms (BDI) and cognitions (ATQ), as well as worry proneness (PSWQ). Given the significant association found between $\mathrm{O}-\mathrm{C}$ and $\mathrm{OCD}$ severity (Y-BOCS), partial correlations controlling for the Y-BOCS total score were also computed. Results are presented in Table 2.

The correlation between $\mathrm{PO}$ and $\mathrm{O}-\mathrm{C}$ scores was non-significant $(r=0.27)$, thus suggesting that they are independent measures of obsessional thoughts. As for the relationships exhibited

Table 1. Descriptive statistics of study measures in men and women".

\begin{tabular}{|c|c|c|c|}
\hline Variables & $\begin{array}{c}\text { Men } \\
(n=14)\end{array}$ & $\begin{array}{l}\text { Women } \\
(n=25)\end{array}$ & $\begin{array}{c}\text { Total } \\
(n=39)\end{array}$ \\
\hline Age & $34.0(12.0)$ & $31.0(7.0)$ & $32.0(9.8)$ \\
\hline OCD duration (years) & $5.5(5.2)$ & $6.4(6.1)$ & $6.1 \quad(5.8)$ \\
\hline Yalo-Brown Obsessive-Compulsive Scale & $28.3(5.1)$ & $25.7(7.5)$ & $26.6(6.8)$ \\
\hline Y-BOCS-Obsessions & $13.9 \quad(2.8)$ & $13.3(3.5)$ & $13.5 \quad(3.2)$ \\
\hline Y-BOCS- Compulsions & $14.4 \quad(2.8)$ & $12,4(4.4)$ & $13.0 \quad(4.0)$ \\
\hline Maudsley Obsessive-Compulsive Inventory & $15.7(7.0)$ & 13.0 & $14.0(6.0)$ \\
\hline Padua Inventory - (PI-WSUR) & $45.3(21.4)$ & $47.4(16.0)$ & $46.7(17.6)$ \\
\hline Revised Obsessional Intrusions Inventory-Total * & $61.3(38.5)$ & $34.5(17.0)$ & $44.2(29.3)$ \\
\hline ROII-Autogenous Subscale* & $32.1(24.7)$ & $17.2(16.6)$ & $22.5(20.9)$ \\
\hline ROIl-Reactive Subscale & $29.1(29.0)$ & $17.5(10.0)$ & $21.6(15.7)$ \\
\hline Obsessive Beliefs Inventory (ICO) & $244.0(34.0)$ & $239.5(41.0)$ & $241.0(38.0)$ \\
\hline White Bear Suppression Inventory (WBSI) & $61.9(9.3)$ & $62.0(7.5)$ & $61.9(8.1)$ \\
\hline Thought Control Questionnaire (TCQ) & $62.0(9.4)$ & $65.7(13.2)$ & $64.4(12.0)$ \\
\hline Beck Depression Inventory (BDI) & $18.3(12.6)$ & $12.8(9.0)$ & $14.8(10.7)$ \\
\hline Automatic Thoughts Questionnaire (ATQ) & $65.3(29.8)$ & $58.2(23.9)$ & $60.7(26.1)$ \\
\hline Penn State Worry Questionnaire (PSWQ) & $65.2(11.2)$ & $62.1(11.8)$ & $63.2(11.6)$ \\
\hline
\end{tabular}

Note: "Data are expressed as Mean (SD). * Significant differences between men and women were found $(p<0.01)$ 
respectively by the $\mathrm{PO}$ and $\mathrm{O}-\mathrm{C}$ scores with the OCD symptom measures, a clearly different pattern of associations emerged. All the obsessional symptom measures were significantly related to the O-C, but the only significant relationship of PO was with the PI-WSUR Harming impulses subscale. With regard to the MOCI, all the subscales correlated with the O-C, although the associations with doubting and slowness disappeared after controlling for OCD severity. Regarding the PI-WSUR, the harming impulses, contamination/washing, checking, and grooming subscales were related to $\mathrm{O}-\mathrm{C}$ before and after controlling for the severity score, with the association between the harming impulses subscale and the O-C being negative.

The O-C showed a greater association with depression measures (BDI and ATQ) than the PO

Table 2. Zero-order (and partial) correlations between autogenous/reactive scores and symptom measures $(N=39)$

\begin{tabular}{lccccc}
\hline Questionnaires & \multicolumn{2}{c}{$\begin{array}{c}\text { Autogenous } \\
\text { Obsessions }\end{array}$} & \multicolumn{3}{c}{$\begin{array}{c}\text { Reactive } \\
\text { Obsessions }\end{array}$} \\
\hline Yale-Brown Obsessive Compulsive Scale & 0.06 & & $0.48^{* *}$ \\
Maudsley Obsessive-Compulsive Inventory (MOCI)-Total & 0.12 & $(0.13)$ & $0.72^{* * *}$ & $(0.55)^{* * *}$ \\
MOCI-Washing & 0.13 & $(0.17)$ & $0.58^{* * *}$ & $(0.53)^{* * *}$ \\
MOCI-Checking & 0.15 & $(0.17)$ & $0.69^{* * *}$ & $(0.59)^{* * *}$ \\
MOCI-Slowness/repetition & 0.03 & $(0.04)$ & $0.48^{* *}$ & $(0.20)$ \\
MOCI-Doubting & 0.13 & $(0.10)$ & $0.40^{* *}$ & $(0.16)$ \\
Padua Inventory (PI-WSUR)- Total score & 0.21 & $(0.23)$ & $0.69^{* * *}$ & $(0.68)^{* * *}$ \\
PI-WSUR- Harming thoughts & 0.04 & $(0.08)$ & -0.14 & $(-0.10)$ \\
PI-WSUR-Harming impulses & $0.80^{* * *}$ & $(0.80)^{* * *}$ & $-0.31^{*}$ & $(-0.31)^{*}$ \\
PI-WSUR-Contamination/washing & -0.07 & $(0.04)$ & $0.77^{* * *}(0.78)^{* * *}$ \\
PI-WSUR-Checking & -0.03 & $(0.03)$ & $0.73^{* * *}$ & $(0.73)^{* * *}$ \\
PI-WSUR-Grooming & -0.22 & $(-0.22)$ & $0.44^{* *}$ & $(0.43)^{* *}$ \\
Beck Depression Inventory & 0.16 & $(0.17)$ & $0.37^{*}$ & $(0.01)$ \\
Automatic Thoughts Questionnaire & 0.06 & $(0.10)$ & $0.47^{* *}$ & $(0.19)$ \\
Penn State Worry Questionnaire & 0.19 & $(0.18)$ & 0.12 & $(-0.21)$ \\
\hline
\end{tabular}

Note: ${ }^{*} p<0.05,{ }^{* *} p<0.01,{ }^{* * *} p<0.001$. Partial correlations after controlling for Y-BOCS are in parentheses.

did, but both coefficients were dropped-out after controlling for OCD severity. Finally, the worry measure (PSWQ) did not show any significant relationship with $\mathrm{PO}$ or with $\mathrm{O}-\mathrm{C}$.

\section{OCD-related beliefs and mental control strategies associated with $P O$ and $O-C$}

In order to examine the differential association of the two modalities of obsessive contents with dysfunctional OCD-related beliefs and thought control (or meta-cognitive) strategies, bi-variate Pearson correlations were computed (see Table 3).

A clearly different pattern of correlations was observed for PO and O-C. The former obsessions were significantly associated with the total score on the dysfunctional beliefs questionnaire (ICO), as well as with dysfunctional beliefs concerning over-responsibility, likelihood-TAF and importance of controlling one's own thoughts. When OCD severity (YBOCS) was controlled, these correlations were maintained and even slightly increased, and two new significant coefficients emerged: Importance of thoughts and Overestimation of harm. In contrast, the O-C subscale was not related to any of the dysfunctional beliefs, before or after controlling for Y-BOCS.

As for the thought control strategies, both the $\mathrm{PO}$ and $\mathrm{O}-\mathrm{C}$ were related to Worry, and the O-C also maintained an association with Reappraisal. An interesting result was the negative association observed between Social control and PO, indicating a greater tendency toward the concealment of those obsessional contents, in comparison with the O-C. When OCD severity was considered, the 
Table 3. Zero-order (and partial) correlations among autogenous/reactive scores, cognitive beliefs and thought control strategies $(N=39)$.

\begin{tabular}{llcc}
\hline Questionnaires & \multicolumn{2}{c}{$\begin{array}{c}\text { Autogenous } \\
\text { Obsessions }\end{array}$} & \multicolumn{2}{c}{ Reactive } \\
Obsessions
\end{tabular}

Note: ICO: Obsessive Beliefs Inventory; TCQ: Thought Control Questionnaire. Partial correlations after controlling for Y-BOCS are in parentheses. ${ }^{*} p<0.05 ;{ }^{* *} p<0.01$

previously observed association between $\mathrm{PO}$ and Worry, as well as the relationship between $\mathrm{O}-\mathrm{C}$ and Reappraisal, were dropped-out. Thus, after controlling for OCD severity, only two correlation coefficients remained significant: the association between $\mathrm{O}-\mathrm{C}$ and Worry, and the negative relationship between $\mathrm{PO}$ and Social control.

\section{Differences between high/low scorers on $A O$}

In order to examine the differences between the OCD patients with the highest rates of autogenous obsessions and those presenting the lowest rate, the subjects were divided into two groups on the basis of the median $(\mathrm{Md}=20)$ score on the AO scale. There were 20 patients in the High AO scorer group, and 19 in the Low AO scorer group. Unpaired t-tests or $\mathrm{chi}^{2}$ (for socio-demographic data) were then computed to examine the significant differences between the two groups across all the study measures.

The results indicate, first, the absence of differences between the two groups in the frequency with which they experienced reactive obsessions ( $t$ $=1.04, p<0.30$ ), thus indicating that the possible differences in the other measures between high and low scorers on AO could be mainly attributable to the frequency with which the autogenous obses- sions are experienced, and not to the frequency of the reactive obsessions.

Between high and low AO scorers, differences were observed on three variables: the High AO scored higher than the Low AO on PI-WSUR Harming impulses, and on beliefs about Likelihood TAF (ICO). In contrast, the Low AO scored higher than the High AO on the strategy of Social Control (TCQ) (see Table 4 for the significant differences).

\section{Differences between high/low scorers on $R O$}

As in the previous analyses, we established two groups of OCD-patients. In this case, the sample was divided on the basis of its median value $(\mathrm{Md}=$ 18) on the reactive scale score on the ROII (High RO: 21 subjects; Low RO: 18 subjects). The two groups did not differ on their AO scores $(t=1.53$; $p<0.14$ ). Unpaired t-tests or $\mathrm{chi}^{2}$ (for socio-demographic data) were then computed to examine the differences between the two groups of patients. The statistically significant differences are shown in Table 4.

The high RO scorers exhibited greater OCD severity than the low RO scorers, as was revealed by the differences obtained in the total score and on the two subscales of the Y-BOCS. The high RO differed also from the low RO on the MOCI and PI- 
Table 4. Significant differences between OCD patients scoring High and Low on Autogenous and Reactive obsessions"

\begin{tabular}{|c|c|c|c|}
\hline Measures & High scorers & Low scorers & $t$ \\
\hline \multicolumn{4}{|c|}{ Autogenous obsessions } \\
\hline PI-WSUR-Harming impulses & $8.18(6.07)$ & $0.77(1.30)$ & $3.57^{* *}$ \\
\hline ICO-TAF likelihood & $19.10(7.85)$ & $14.58(5.85)$ & 2.04* \\
\hline TCQ-Social Control & $10.95(4.21)$ & $13.63(4.03)$ & $-2.03^{*}$ \\
\hline \multicolumn{4}{|c|}{ Reactive obsessions } \\
\hline Y-BOCS- Total score & $29.71(5.91)$ & $23.6(6.46)$ & $2.88^{* *}$ \\
\hline Y-BOCS Obsessions & $14.71(2.93)$ & $12.33(3.21)$ & $2.27^{*}$ \\
\hline Y-BOCS Compulsions & $15.01(3.11)$ & $11.33(4.04)$ & $2.99 * *$ \\
\hline MOCI- Total score & $16.60(5.42)$ & $11.21(5.46)$ & $3.09 * *$ \\
\hline MOCI-Washing & $4.85(3.10)$ & $3.00(2.47)$ & $2.05^{*}$ \\
\hline MOCI-Checking & $6.05(1.79)$ & $3.63(1.86)$ & $4.13^{* * * *}$ \\
\hline PI-WSUR-Total score & $53.91(17.28)$ & $37.78(14.10)$ & $2.30^{*}$ \\
\hline PI-WSUR Contam./Washing & $13.64(9.09)$ & $6.11(6.31)$ & $2.10^{*}$ \\
\hline PI-WSUR-Checking & $25.45(7.47)$ & $12.67(7.53)$ & $3.79 * * *$ \\
\hline Automatic Thoughts (ATQ) & $68.29(30.4)$ & $51.50(16.6)$ & $2.12^{*}$ \\
\hline ICO-Intolerance Uncertainty & $38.75(6.20)$ & $34.53(5.47)$ & $2.25^{*}$ \\
\hline ICO-Perfectionism & $53.65(12.59)$ & $43.16(10.54)$ & $2.81^{* *}$ \\
\hline TCQ-Worry & $11.50(3.74)$ & $9.11(2.18)$ & $2.46^{*}$ \\
\hline
\end{tabular}

Note: "Data are expressed as mean (SD). * $p<0.05 ; * * p<0,01$;

WSUR total scores, with the main source of differences being attributable to the Checking and Washing symptom subscales of both questionnaires. The High scorers also scored higher on the Automatic Thoughts Questionnaire. With regard to dysfunctional beliefs and thought control strategies, the high RO scorers exhibited more Intolerance to uncertainty and Perfectionism than the low RO, and they made more use of Worry as a strategy to control the thoughts.

\section{DiSCUSSION}

The general aim of the study was to test the OCD autogenous-reactive model in a group of OCD patients, given that to date the only empirical evidence on that model has been drawn from normal samples.

As in previous studies with Spanish non-clinical and sub-clinical OCD participants (Belloch et al., 2004; Morillo et al., 2003), men scored higher than women on the frequency with which they experienced autogenous obsessions. This increased frequency of $A O$ in the $O C D$ men presumably also explains their higher rating on the number and frequency of obsessional intrusive thoughts (total sco- re on the ROII). These between-gender differences may be attributable to the nature of the autogenous themes, which traditionally have been ascribed more to men than to women. However, perhaps an excessive frequency of these thought contents are experienced as highly aversive by the OCD men. In any case, this gender difference raises a variety of intriguing questions, which go far beyond the purpose and scope of the present study.

We did not obtain a significant relationship between the contents of $A O$ and those of RO. This result suggests that the two types of obsessional themes are relatively independent of each other, which supports considering them as two different subtypes of OCD symptoms, as has long been postulated by Rachman (Rachman, 1997, 1998, 2003; Rachman \& Hodgson, 1980; Rachman \& Shafran, 1998). However, the categorical consideration of $A O$ and $R O$ does not mean that a particular $O C D$ patient must be exclusively ascribed to one subtype or the other. In fact, our OCD patients reported having both modalities of symptoms, even though the intensity (frequency) with which $\mathrm{AO}$ or $\mathrm{RO}$ was experienced was different among the patients, thus indicating a dimensional characterization of these OCD subtypes and the need to explore the presence of both $A O$ and $R O$ in a particular subject. 
The absence of associations between AO contents and the three most widely used instruments to assess OCD severity could indicate that these instruments are not designed to adequately evaluate the presence of aggressive, sexual and blasphemous obsessional themes, which are the classical themes of pure or cognitive obsessions and the main obsessional symptoms of between 20 and $30 \%$ of OCD patients (Stein, Forde, Anderson, \& Walker, 1997). There was only one measure clearly associated with the $\mathrm{AO}$ themes, the Harming impulses subscale from the Padua Inventory. However, surprisingly, there was no relationship between the $\mathrm{AO}$ and the Harming thoughts subscale. This result could be explained in light of the great heterogeneity of the item contents: while some of them track autogenous themes («I get upset and worried at the sight of knives, daggers, and other pointed objects")), others record reactive contents ( $« I$ imagine catastrophic consequences as a result of absent-mindedness or minor errors that I make»). Additionally, this subscale did not correlate with the RO either, and in the validation study (Burns et al., 1996) it shared a large amount of variance with the Checking compulsions subscale, whereas the Harming impulses subscale shared the least amount of variance with the other 4 subscales. In short, the only measure that adequately recorded autogenous obsessive themes was the Harming Impulses subscale from the Padua Inventory, which in turn was negatively associated with the RO.

In contrast, the $\mathrm{OCD}$ instruments maintained high correlations with the reactive obsessional themes, indicating an over-representation of these contents in the clinical measures. In our opinion, these results could indicate a limitation of the instruments commonly used to differentiate OCD patients on the basis of their obsessional contents. It could also partially explain the inconsistencies found when conducting research to identify OCD subtypes, especially for the harming, sexual and blasphemous obsessional modalities. The AO are hypothetically associated with covert OCD symptoms, whereas reactives are related to overt behavioural features (Lee \& Telch, 2005): if this suggestion is true, then the instruments commonly used to record $\mathrm{OCD}$ symptoms do not adequately map the autogenous obsessions.

The reactive obsessions, but not the autogenous ones, were associated with depressive symptoms. However, this association disappeared when OCD severity was controlled. These data indicate that the frequently reported co-morbidity between $O C D$ and Depression could be partially explained in terms of OCD severity; that is, high levels of $O C D$ severity could be accompanied by a dysphoric mood, but this does not mean that a real co-morbidity between the two disorders is currently present. In fact, the mean score of our patients on the BDI did not indicate the presence of a clinically significant score on depression. In any case, it is also possible that the patients with $R O$ have a greater tendency to exhibit symptoms of depression secondary to $\mathrm{OCD}$. If the RO are most linked to compulsive behaviours, it is possible that these behaviours cause greater interference in the daily activities of the patients and, hence, can affect their mood state.

Neither the autogenous nor the reactive obsessions were related to worry proneness (PSWQ). In contrast, Lee, Lee, Kim, Kwon, \& Telch (2005) reported a significant relationship between $R O$ and PSWQ in their normal participants. This discrepancy between our results and those reported by the above-mentioned authors could be explained if we take into account the differences between the two studies in the sample studied. In fact, in a study with Spanish non-clinical subjects (Belloch, Morillo, \& Garcia-Soriano, 2005, submitted), there was a weak but significant association between PSWQ and RO, as in the Lee et al. (2005) study with non-clinical participants. It must be noted that the PSWQ measures a general and non-specific tendency to worry, but it does not measure worry as a strategy to control obsessions.

Regarding the associations of $\mathrm{AO}$ and $\mathrm{RO}$ with OCD-related beliefs, the results indicate that the $A O$ contents maintained a wide variety of relationahips with dysfunctional beliefs. This result indicates that high scores on AO are associated with high values on Responsibility, Importance of thoughts, Likelihood-TAF, Importance of controlling the thoughts and Overestimation of harm. These findings support the notion that the cognitive or pure obsessions, well exemplified in the AO contents, are closely related to several meta-cognitive dysfunctional beliefs. Salkovskis $(1985,1989,1999)$ has emphsized the role of responsibility appraisals in the development and persistence of $O C D$, and his suggestion has been empirically supported by experimental studies (e.g., Ladouceur et al., 1995; Lopatka \& Rachman, 1995), and psychometric studies (e.g., Foa, Sacks, Tolin, Preworski, \& Amir, 2002; Salkovskis et al., 2000) with both OCD and non OCD samples. 
The Likelihood-TAF has also been shown to be a dysfunctional belief characteristic of OCD patients in many studies (Amir, Freshman, Ramsey, Neary, \& Brigidi, 2001; Emmelkamp \& Aardema, 1999; Rachman, 1993; Rassin, Diepstraten, Merckelbach, \& Muris, 2001; Rassin, Merckelbach, Muris, \& Schmidt, 2001). Even though it was considered by Salkovskis (1985) as an example of the most general belief of Responsibility for harm, it was later postulated as a separate belief from Responsibility (Rachman, 1993), as well as an internal trigger for appraisals of responsibility for harm (Shafran \& Rachman, 2004). As the cognitive models of OCD have developed, the TAF has occupied a central place as a high-risk or vulnerability factor in developing catastrophic misinterpretations of the significance of intrusive thoughts, although it is not considered necessary or sufficient for the maintenance of $O C D$. In the most exhaustive review published about this belief (Shafran \& Rachman, 2004), the authors conclude that the Likelihood form of TAF, compared to the Moral form, is robust in explaining the $\mathrm{OCD}$, even though it also plays a relevant role in other anxiety disorders (Hazlett-Stevens, Zucker, \& Craske, 2002; Rassin et al., 2001a, 2001b). In our study, the TAF-probability was not only related to the $\mathrm{AO}$ score, but it was also able to discriminate between high and low scorers on these obsessions. However, as we do not include patients other than OCD, we cannot explore the specificity of this belief to OCD. Moreover, the crosssectional design of our study does not allow us to formulate any hypotheses about the etiological role of Likelihood-TAF in OCD. However, its robust relationship with the aggressive, sexual, and blasphemous obsessional symptoms suggests an important and specific role in the maintenance of these specific obsessional contents compared to the reactive ones. These data suggest that the LikelihoodTAF plays a central role in some forms or subtypes of OCD, but not in others. Therefore, the non-specificity of that belief in most studies could be due to the consideration of the OCD as a unitary disorder. In order to examine this suggestion, it is necessary to design studies that compare subtypes of OCD with other mental disorders.

The other two belief domains related to the AO, Importance of Thoughts and Importance of control, have a long tradition in the conceptualization of OCD (Thordarson \& Shafran, 2002), and they are conceived as a core belief system underlying the pathogenesis of OCD. The Importance of Thoughts, as measured in the Obsessional-Beliefs Questionnaire (OCCWG, 1997, 2001) and in the Interpretation of Intrusions Inventory (OCCWG, 1997, 2001), has proved its utility in discriminating OCD patients from other anxious controls (OCCWG, 2001). In a similar way, the Thought Control factor from the Meta-Cognitive Beliefs Questionnaire (Clark, Purdon, \& Wang, 2003), shown to be a significant predictor of the frequency of obsessions, was the only belief that predicted obsessional symptoms in non-clinical subjects, and it was able to discriminate between OCD patients and non-clinical controls (Clark \& Purdon, 1995).

Finally, the Overestimation of threat has for long time been postulated as an important factor in the development and maintenance of anxiety disorders in general, and obsessions in particular (e.g., Carr, 1971, 1974; Kozak et al., 1987; Rachman, 1997, 1998). In our study, this core belief found in anxiety disorders was only associated with $\mathrm{AO}$ after controlling for OCD severity. To adequately assess this belief in $O C D$, it might be necessary to make use of more specific evaluation instruments containing items directly related to the feared threat for a particular patient. As Sookman \& Pinard (2002) pointed out, this belief could be conceived at two different but related levels: as belief and as appraisal. From a general level (belief), it is common to many anxiety disorders, but in order to assess its importance in a particular disorder (as appraisal) it is necessary to relate it directly to the content of the feared event. Even though the distinction between core beliefs and specific appraisals is not exclusive to the Over-estimation of Harm (OCCWG, 1997), it is also possible that this differentiation could be more crucial for some beliefs and /or anxiety disorders than for others.

In summary, our results regarding a robust association between several dysfunctional beliefs and OCD symptoms confirm those previously reported in studies analyzing the relevance of several metacognitive beliefs in OCD, but only when the contents of classical «pure obsessions» are taken into account. In contrast, no significant associations between the dysfunctional beliefs and the RO were found. This result casts doubt on the importance of these beliefs in the development and/or in the maintenance of reactive obsessive symptoms. However, it must also be noted that when the OCD patients were divided into low and high scorers on the RO symptoms, Intolerance to uncertainty and Perfectionism were able to discriminate between the two 
RO groups. Dysfunctional Perfectionism, conceived as the psychopathological end of functional or normal perfectionism (Rhéaume et al., 1995), has been postulated as a risk factor for OCD (Rasmusen \& Eissen, 1989), but also for other behavioural and mental disorders (e.g., eating disorders, suicidal tendencies, social phobia). Of the various components included in the perfectionism concept (Hewitt \& Flett, 1991), socially prescribed perfectionism is the one most clearly associated with OCD (Antony, Purdon, Huta \& Swinson, 1998; Shafran \& Mansell, 2001). On the other hand, Guidano \& Liotti (1983) postulated that in OCD perfectionism takes the form of a need for certainty rather than a need to control. In line with that proposal, our data reveal that perfectionism and intolerance to uncertainty are the two only beliefs that play a role in the reactive obsessional symptoms. However, it is also possible that Intolerance to uncertainty is not specific to $O C D$, as has been recently informed in the study by Holaway, Heimberg, \& Coles (2006). This study reports that two groups of subjects, sub-clinical or analogous to OCD and generalized anxiety disordered, do not differ on this belief. In short, the published results about these two belief domains, Perfectionism and Intolerance to Uncertainty, suggest that there are common dysfunctional beliefs in OCD subjects with reactive obsessions, but that they are also present in other emotional disorders (e.g., anxiety, depression, and some forms of eating disorders). If this conclusion is confirmed, the specificity of these beliefs to the two subtypes of $O C D, A O$ and $R O$, is questionable.

With regard to the thought control strategies, we observed a different pattern for the two hypothesized subtypes of obsessions. The AO were consistently related to the non-use of the Social Control strategy. This result indicates that these obsessive contents are not overtly manifested by the patients, suggesting a marked tendency to conceal these obsessions, which increases as their frequency increases (the High $\mathrm{AO}$ differed from the Low AO). The concealment of obsessions, defined as «the action to deliberately hide from other people the content and frequency of one's obsessions» (Newth \& Rachman, 2001, pp. 457), is an important and frequently overlooked aspect in $\mathrm{OCD}$, and it has been explained on the basis of the catastrophic misinterpretations that patients attach to their obsessions. Among the consequences derived from the concealment of obsessions, Newth \& Rachman (2001) suggest that patients might think that disclo- sing their obsessions is equivalent to losing control of their thoughts. This suggestion receives support from our results, as the Importance of controlling the thoughts was a core belief related to the AO.

In contrast, the $R O$ were strongly associated with worry as a thought control strategy. In the Lee et al. (2004) study, the authors suggested that the RO were associated with the tendency to be worried, with that tendency being a common aspect in OCD and Generalized Anxiety. Our results partially support that suggestion because, as mentioned above, we did not find a significant relationship between the worry measure (PSWQ) and RO. However, if we consider that the high frequency of some $R O$ contents (washing, checking, and contamination) was linked to intolerance to uncertainty and perfectionism beliefs, then the association between RO and worry as a thought control strategy could be understood as an attempt to reduce the uncertainty associated with the behaviours the patients actively develop (checking, avoiding contaminants, or washing themselves) in order to keep their obsessions under control. In addition, the more perfectly these behaviours are performed, the higher the probability of reducing the uncertainty. Under these circumstances, being alert and worried in order to avoid or prevent the disaster stemming from a defective behaviour is the best control strategy that can be employed.

In conclusion, our results support the feasibility of differentiating between two modalities of obsessive symptoms on the basis of their respective contents: one referring to aggressive, sexual and blasphemous/immoral themes, and the other characterized by contamination, mistakes, accidents, and asymmetry or disarrayed contents. The former are more strongly associated with covert or cognitive symptoms (e.g. unwanted unacceptable thoughts), whereas the second are more linked to overt/behavioural OCD symptoms (e.g., behaviours of checking, washing and ordering).

The first group of obsessions is consistently related to several dysfunctional beliefs: responsibility, overestimation of threat, and meta-cognitive beliefs (importance of thoughts, likelihood-TAF, importance of controlling), and, as well as to a tendency to conceal them. These kinds of obsessions are not well-represented in the current diagnostic instruments. This fact may lead to underestimating not only their severity, but also their mere presence, and its potential importance in the aetiology and/or maintenance of the $\mathrm{OCD}$. Consequently, there may 
be a lack of efficacy in the current treatments for OCD. In contrast, the other subgroup of obsessions maintains weak associations with the dysfunctional beliefs proposed at the core of the most influential current cognitive models for $\mathrm{OCD}$, which suggests that these approaches might be useful and adequate in explaining the former group of obsessions, but they would be only moderately useful for understanding the latter.

\section{REFERENCES}

Abramowitz, J., Franklin, M., Schwartz, S.A., \& Furr, J.M. (2003). Symptom presentation and outcome of cognitive-behavioral therapy for obsessive-compulsive disorder. Journal of Consulting and Clinical Psychology, 71, 1049-1057.

Abramowitz, J.S., Whiteside, S., Lynam, D., \& Kalsy, S. (2003). Is thought action fusion specific of obsessivecompulsive disorder? a mediating role of negative affect. Behaviour Research and Therapy, 41, 1069-1079.

American Psychiatric Association (2000). Diagnostic and Statistical Manual of Mental Disonders fourth editionText revision). Washington, D.C.: American Psychiatric Association.

Amir, N., Freshman, M., Ramsey, B., Neary, E., \& Brigidi, B. (2001). Thought-action fusion in individuals with OCD symptoms. Behaviour Research and Therapy, 39, 765-776.

Antony, M.M., Purdon, C.L., Huta, V., \& Swinson, R.P. (1998). Dimensions of perfectionism across the anxiety disorders. Behaviour Research and Thenapy, 36, 1143 . 1154.

Beck, A.T., Rush, A.J., Shaw, B.F., \& Emery, G. (1979). Cognitive Therapy of Depression. New York: Guilford Press.

Belloch, A., Cabedo, E., Morillo, C., Lucero, M., \& Carrio, C. (2003). Designing a new instrument to assess dysfunctional beliefs of the obsessive-compulsive disorder: preliminary results of the Obsessive Beliefs Inventory. International Joumal of Clinical and Health Psychology, 3, 235-250

Belloch, A., Morillo, C., Lucero, M., Cabodo, E., \& Carrió, C. (2004). Intrusive thoughts in non-clinical subjects: the role of frequency and unpleasantness on appraisal ratings and control strategies. Clinical Psychology and Psychotherapy, 11, 100-110.

Belloch, A., Morillo, C., \& García-Soriano, G. (submitted). The influence of obsessional subtypes: testing the autogenous/reactive model of obsessions.

Burns, G.L., Keortge, S.G., Formea, G.M., \& Sternberg, L.G. (1996). Revision of the Pactua Inventory of obsessive comptilsive disorder symptoms: Distinctions between worry, obsessions, and compulsions. Behaviour
Research and Therapy, 34, 163-173.

Cabedo, E., Belloch, A., Morillo, C., Giménez, A., \& Carrió, C. (2004). Increasing dysfunctional beliefs as obsessionality increases. International Journal of Clinical and Health Psychology, 4, 465-479.

Calamari, J.E., Wiegartz, P.S., \& Janeck, A.S. (1999). Obsessive-compulsive disorder subgroups: a symptombased clustering approach. Behaviour Research and Therapy, 37, 113-125.

Calamari, J.E., Wiegartz, P.S., Riemann, B.C., Cohen, R.J., Greer, A., Jacobi, D.M., et al. (2004). Obsessive-compulsive disorder subtypes: an attempted replication and extension of a symptom-based taxonomy. Behaviour Research and Therapy, 42, 647-670.

Carr, A.T. (1971). Compulsive neurosis: Two psychological studies. Bulletin of the British Psychological Society, 24, 256-257.

Carr, A.T. (1974). Compulsive neurosis: A review of the literature. Psychological Bulletin, 81, 311-318.

Carrió, C. (2004). Efectos a largo plazo del tratamiento cognitivo en un caso de trastorno obsesivo-compulsivo. Revista de Psicopatologia y Psicologia Clínica, 9, 99-122.

Clark, D. A., \& Purdon, C. L. (1995). The assessment of unwanted intrusive thoughts: $A$ review and critique of the literature. Behaviour Research and Therapy, 33, 967-976.

Clark, D. A., Purdon, C. L., \& Wang, A. (2003). The MetaCognitive Beliefs Questionnaire: development of a measure of obsessional beliefs. Behaviour Research and Therapy, 41, 655-669.

Denys, D., de Geus, F., van Megen, H.J., \& Westnberg, H.G.M. (2004). Use of factor analysis to detect potential phenotypes in obsessive-compuslive disorder. $P$ sychiatry Research, 128, 273-280.

Di Nardo, P.A., Brown, T.A., \& Barlow, D.H. (1994). Anxiety Disorders Interview Schedule for DSM-IV: Lifetime version (ADIS-IV-L). New York: Graywind Publications Incorporated.

Emmelkamp, P., \& Aardema, A. (1999). Meta-cognition, specific obsessive-compulsive beliefs and obsessivecompulsive behaviour. Clinical Psychology and Psychotherapy, 6, 319-145.

Faull, M., Joseph, S., Meaden, A., \& Lawrence, T. (2004). Obsessive beliefs and their relation to obsessive-compulsive symptoms. Clinical Psychology and Psychotherapy, 11, 158-167.

Foa, E.B., Sacks, M.B., Tolin, D.F., Preworski, A., \& Amir, N. (2002). Inflated perception of responsibility for harm in OCD patients with and without checking compulsions: a replication and extension. Journal of Anxiety Disorders, 16, 443-453.

Frost, R.O., \& Steketee, G. (2000). Issues in the treatment of compulsive hoarding. Cognitive and Behavional Practice, 6, 397-407.

Gimenez, A., Morillo, C., Belloch, A., Carrib, C., \& Cabedo, E. (2004). Creencias disfuncionales asociadas a 
síntomas obsesivo-compulsivos: una aproximación a la especificidad. Revista de Psicopatologia y Psicologia Clínica, 9, 1-17.

Goodman, W.K., Price, L.H., Rasmussen, S.A., \& Mazure, C. (1989a). The Yale-Brown Obsessive-Compulsive Scale (I): Development, use and reliability. Archives of General Psychiatry, 46, 1006-1011.

Goodman, W.K., Price, L.H., Rasmussen, S.A., \& Mazure, C. (1989b). The Yale-Brown Obsessive-Compulsive Scale (II): Validity. Archives of General Psychiatry, 46, 1012-1016.

Guidano, V., \& Liotti, G. (1983). Cognitive processes and emotional disorders. New York: Guilford.

Hazlett-Stevens, H., Zucker, B.G., \& Craske, M.C. (2002). The relationship of thought-action fusion to pathological worry and generalized anxiety disorder. Behaviour Research and Therapy, 40, 1199-1204

Hewitt, P.L., \& Flett, G.L. (1991). Perfectionism in the self and social contexts: Conceptualization, assessment, and association with psychopathology. Journal of Personality and Social Psychology, 60, 456-470.

Hodgson, R.J., \& Rachman, S. (1977). Obsessional compulsive complaints. Behaviour Research and Therapy, 15, 389-395.

Holaway, R.M., Heimberg, R.G., \& Coles, M.E. (2006). A comparison of intolerance to uncertainty in analogue obsessive-compulsive disorder and generalized anxiety disorder. Journal of Anxiety Disorders, 20, 158-174.

Hollon, S. D., \& Kendall, P. C. (1980). Cognitive self-statements in depression: development of an automatic thoughts questionnaire. Cognitive Therapy and Research, 4, 383-395.

Ibáñez, I., Olmedo, E., Peñate, W., \& González, M. (2002). Obsesiones y compulsiones: estructura del Inventario de Padua. International Journal of Clinical and Health Psychology, 2, 263-288.

Kozak, M.J., Foa, E.B., \& McCarthy, P. (1987). Asessement of Obsessive compulsive disorder. In C. Last, \& M. Hersen (Eds.), Handbook of anxiety disorders (pp. 87-108). New York: Pergamon Press.

Kyrios, M., Steketee, G., Frost, R.O., \& Oh, S. (2002). Cognitions in compulsive hoarding. In R.O. Frost \& G. Steketee (Eds.). Cognitive approaches to obsessions and compulsions. Theory, Assessment and Treatment (pp. 269-288). Oxford: Elsevier.

Ladouceur, R., Rhéaume,J., Freeston, M.H., Aublet, F., Jean, K., Lachance, S., et al. (1995). Experimental manipulations of responsibility: An analogue test for models of obsessive-compulsive disorder. Behaviour Research and Therapy, 33, 937-946.

Leckman, J.F., Grice, D.E., Boardman, J., Zhang, H., Vitale, A., Bondi, C., Alsobrook, J., et al. (1997). Symptoms of obsessive-compulsive disorder. American Journal of Psychiatry, 154, 911-917.

Lee, H.J., \& Kwon, S.M. (2003). Two different types of obsessions: autogenous obsessions and reactive obsessions. Behaviour Research and Therapy, 41, 11-29

Lee, H-J., \& Telch, M.J. (2005). Autogenous/reactive obsessions and their relationship with OCD symptoms and schizotypal personality features. Journal of Anxiety Disonders, 19, 793-805.

Lee, H-J., Lee, S-H., Kim, H-S., Kwon, S-M., \& Telich, M.J. (2005). A comparison of autogenous/reactive obsessions and worty in a nonclinical population: a test of the continuum hypothesis. Behaviour Research and Therapy, 43, 999-1010.

Lopatka, C., \& Rachman, S. (1995). Perceived responsibility and compulsive checking: an experimental analysis. Behaviour Research and Therapy, 33, 673-684.

Lucero, M. (2002). Pensamientos intrusivos en población general (Intrusive thoughts in general population). University of Valencia. Doctoral Dissertation Thesis.

Luciano, J.V., Belloch, A., Algarabel, S., Tomás, J.M., Morillo, C., \& Lucero, M. Thought suppression and strategies to control unwanted thoughts: A confirmatory factor-analytic study in a Spanish non-clinical sample. European Journal of Psychological Assessment.

Marks, I. (1987). Fears, phobias and rituals. Panic, anxiety and their disorders. New York: Oxford University Press.

Mataix, D., Rauch, S.L., Manzo, P.A., Jenije, M.A., \& Baer, L. (1999). Use of factor-analyzed symptom dimensions to predict outcome with serotonin reuptake inhibitors and placebo in the treatment of obsessive-compulsive disorder. American Journal of Psychiatry, 156, 1409-1416.

Mataix, D., Rosario, M.C., \& Leckman, J.F. (2005). A multidimensional model of Obsessive-Compulsive Disorder. American Journal of Psychiatry, 162, 228238.

Meyer, T.J., Miller, M.L., Metzger, R.L., \& Borkovec, T.D. (1990). Development and validation of the Penn State Worry Questionnaire. Behaviour Research and Therapy, 28, 487-495.

Morillo, C., Giménez, A., Belloch, A., Lucero, M., Carrib, C., \& Cabedo, E. (2003). Pensamientos intrusos en obsesivos subclínicos: contenidos, valoraciones y estrategias de control. Revista de Psicopatologia y Psicologia Clinica, 8, 23-38.

Newth, S., \& Rachman, S. (2001). The concealment of obsessions. Behaviour Research and Therapy, 39, 457 464.

Obsessive Compulsive Cognitions Working Group (1997). Cognitive assessment of obsessive-compulsive disorder. Behaviour Research and Therapy, 35, 667-681.

Obsessive Compulsive Cognitions Working Group (2001). Development and initial validation of the Obsessive Beliefs Questionnaire and the Interpretation Intrusions Inventory. Behaviour Research and Therapy, 39, 9871005 . 
Purdon, C., \& Clark, D. (1993). Obsessive intrusive thoughts in non-clinical subjects. Part I. Content and relation with depressive, anxious, and obsessional symptoms. Behaviour Research and Therapy, 31, 713-720.

Purdon, C., \& Clark, D. (1994). Obsessive Intrusive thoughts in non-clinical subjects. Part II. Cognitive appraisal, emotional response and thought control strategies. Behaviour Research and Therapy, 32, 403-410.

Rachman, S. (1993). Obsessions, responsibility and guilt. Behaviour Research and Therapy, 31, 149-154.

Rachman, S. (1997). A cognitive theory of obsessions. Behaviour Research and Therapy, 35, 793-802.

Rachman, S. (1998). A cognitive theory of obsessions: elaborations. Behaviour Research and Therapy, 36, 385-401.

Rachman, S. (2002). A cognitive theory of compulsive checking. Behaviour Research and Therapy, 40, 625639.

Rachman, S. (2003). The treatment of Obsessions. New York: Oxford University Press.

Rachman, S.J., \& Hodgson, R.J. (1980). Obsessions and compulsions. New York: Prentice Hall.

Rachman, S., \& Shafran, R. (1998). Cognitive and behavioural features of OCD. In R. Swinson, M.A. Antony, S. Rachman, \& M.A. Richter (eds.) Obsessive-compulsive disorder: theory, research and treatment (pp. 51-78). New York: Guilford Press,

Rasmussen, S., \& Eisen, J.L. (1989). Clinical features and phenomenology of obsessive compulsive disorder. Psychiatric Annals, 19, 67-73.

Rassin, E., Diepstraten, P., Merckelbach, H., \& Muris, P. (2001a). Thought-action fusion and thought suppression in obsessive-compulsive disorder. Behaviour Research and Therapy, 39, 757-764.

Rassin, E., Merckelbach, H., Muris, P., \& Schmidt, H. (2001b). The thought-action fusion scale: further evidence for its reliability and validity. Behaviour Research and Therapy, 39, 537-544.

Rhéaume, J., Freeston, M.H., Dugas, M.J., Letarte, H., \& Ladouceur, R. (1995). Perfectionism, responsibility, and obsessive-compulsive symptoms. Behaviour Research and Therapy, 33, 785-794.

Salkovskis, P.M. (1985). Obsessional-compulsive problems: a cognitive-behavioural analysis. Behaviour Research and Therapy, 23, 571-583.

Salkovskis, P.M. (1989). Cognitive-behavioral factors and the persistence of intrusive thoughts in obsessional problems. Behaviour Research and Therapy, 27, 677-682.

Salkovskis, P.M. (1999). Understanding and treating obsessive-compulsive disorder. Behaviour Research and Therapy, 37, 29-52.
Salkovskis, P.M., Wroe, A.L., Gledhill, A., Morrison, N., Forrester, E., Richards, et al. (2000). Responsibility attitudes and interpretations are characteristic of obsessive compulsive disorder. Behaviour Reseanch and Therapy, 38, 347-372.

Sandín, B., \& Chorot, P. (1991). Adaptación española del Penn State Worry Questionnaire (PSWQ). (Spanish adaptation of the Penn State Worry Questionnaire). Madrid: UNED,

Shafran, R., \& Mansell, W. (2001). Perfectionism and psychopathology. Clinical Psychology Review, 21, 879 906.

Shafran, R., \& Rachman, S. (2004). Thought-action fusion: a review. Journal of Behavior Therapy and Experimental Psychiatry, 35, 87-107.

Shafran, R., Thordarson, D.S., \& Rachman, S. (1996). Thought-action fusion in obsessive compulsive disorder. Journal of Anxiety Disorders, 10, 379-391.

Sookman, D., \& Pinard, G. (2002). Overestimation of threat and intolerance of uncertainty in obsessive compulsive disorder. In R.O. Frost \& G. Steketee (eds.). Cognitive approaches to obsessions and compulsions. Theory, Assessment and Treatment. (pp. 63-89). Oxford: Elsevier.

Stein, M., Forde, D., Anderson, G., \& Walker, J. (1997). Obsessive compulsive disorder in community: an epidemiological survey with clinical reappraisal. American Journal of Psychiatry, 154, 1120-1126.

Summerfeldt, L.J., Richter, M.A., Antony, M.M., \& Swinson, R.P. (1999). Symptom structure in obsessive-compulsive disorder: a confirmatory factor-analytic study. Behavior Research and Therapy, 37, 297-311.

Taylor, S.E., Abramowitz, J.S., McKay, D., Calamari, J.E., Sookman, D., Kyrios, M., et al. (2006). Do dysfunctional beliefs play a role in all types of obsessive-compulsive disorder?. Journal of Anxiety Disorders, 20, 8597.

Thordarson D.S., \& Shafran, R. (2002). Importance of Thoughts. In R.O. Frost \& G. Steketee (Eds.), Cognitive Approaches to Obsessions and Compulsions: Theory, Assessment and Treatment (pp. 15-28). Oxford: Elsevier.

Tolin, D.F., Woods, C.M., \& Abramowitz, J.S.(2003). Relationship between obsessive beliefs and obsessivecompulsive symptoms. Cognitive Therapy and Research, 27, 657-669.

Wegner, D.M., \& Zanakos, S. (1994). Chronic thought suppression. Joumal of Personality and Social Psycho$\log y, 62,615-640$.

Wells, A., \& Davies, M.I. (1994). The thought control questionnaire: A measure of individual differences in the control of unwanted thoughts. Behaviour Research and Therapy, 32, 871-878. 